\title{
The relevance of temporal iconicity with instruction manuals for elderly users
}

\author{
Alexander Mertens ${ }^{\mathrm{a},}$, Claudia Nick ${ }^{\mathrm{a}}$, Stefan Krüger ${ }^{\mathrm{b}}$ and Christopher M. Schlick ${ }^{\mathrm{a}}$ \\ ${ }^{a}$ Chair and Institute of Industrial Engineering and Ergonomics of RWTH Aachen University, \\ Bergdriesch 27, 52062 Aachen, Germany \\ ${ }^{b}$ Medical Clinic I, Medical Faculty, RWTH Aachen, Pauwelsstraße 30,52074 Aachen, Germany
}

\begin{abstract}
Gerontolinguistic obtains a growing importance with the increase of elderly users due to Demographic Change. Since acceptance and ease of use of supportive systems for elderly, such as "E-Nursing-Assistants", are highly dependent on the age suitable design of readable instructions, an age-appropriate linguistic concept is of high value for usability. There has been only little research on the relevance of foreign words, signal words, textual arrangement, optical accentuation of key terms and temporal iconicity concerning older users. Thus, an efficient design of age suitable manual instructions within a medical context still remains to be done. The objective of this research was to evaluate the relevance of the previously mentioned factors in the context of written instructions. For this, an empirical survey was designed which was given to 45 study participants. The subjects of the experiment were given $4 \times 3$ instructions after a pretest questionnaire. The aim was to execute these instructions as correctly and quickly as possible. Furthermore the instructions were rated regarding comprehensibility with a retrospective questionnaire.
\end{abstract}

Keywords: readability, 50+, temporal iconicity, linguistic factors, layout factors

\section{Introduction}

Heterogeneity among the elderly population must be identified as one of the main characteristics of this age group. Different biographies, educational standards and diseases make it very difficult to speak of "the" group of elderly. Still, it is commonly agreed on that with growing age, cognitive and physiological capacity changes occur. These changes often alter self-reliance. New technologies challenge these changes and offer the opportunity of an autonomous lifestyle. Thus, a special demand is given to the design of manual instructions. A technology may offer the most convenient solution, but if the target group does not comprehend accordingly a benefit will not occur. Wirtz, Jakobs and Ziefle [1] have identified 20 types of usability problems and assigned them to 5 categories. These categories are coherence, feedback, layout, structural and linguistic factors. This study analyzes 3 of these categories: layout, structure and linguistic factors.

\subsection{Structural factors}

The problem occurring with structural design concerns the overall design of content. For this study the aspect of temporal iconicity was evaluated.

\subsubsection{Temporal iconicity}

As proven by Smith et al., a non-chronological text structure lowers comprehension relative to a text which is structured according to the chronological order of its content [2]. The latter describing temporal iconicity. Enkvist defined temporal iconicity as given"... whenever the linear relations in a text stand for temporal (...) relations between the referents in the world described by that text [3]. A famous example for temporal iconicity can be found in Haspelmath [4], where he exemplified iconicity with the famous dictum "Veni, vidi, vici" (He came, he saw,

* Corresponding author. E-mail: a.mertens@iaw.rwth-aachen.de 
he conquered). Contrary, "Prior to his victory, he came and saw", would be a non iconic expression.

Until now, there are diverging results and interpretations on the relevance of temporal iconicity. Whilst Van Horen et al. clearly say that "the results (...) suggest that temporal iconicity of instructions is not helpful" [5], Maxim and Bryan investigated that "sentences in which the order of mention was the same as the order of occurrence were significantly easier to understand than sentences where the order of mention was not the order of occurrence" [6].

Regarding the fact that with increasing age shortterm memory capacities decrease [7] and non iconic sentences place a high cognitive load on the reader, since the reader has to store information in his memory, in order to reconstruct the sequence of occurrence, elderly should highly benefit from temporal iconicity in texts. Thus temporal iconicity must be a central design factor if cognitive change in age is considered within text comprehension. As a result this factor was given priority during the test phase of this study.

\subsection{Linguistic factors}

The analyzed linguistic factors during testing were the use of foreign- and signal words as well as the use of passive voice.

\subsubsection{Foreign words}

A survey carried out by Jakobs et al. [8] investigated interfering factors of instruction manuals. $45.8 \%$ of participants stated that the manual was incomprehensible. The reason for this being technical expressions, acronyms or other unknown items and terms. Similarily, ETSI 2006 user education guidance and guidelines discusses the use of inappropriate language [9].

An important aspect of textual comprehension is the awareness level of used terms: "It is obvious that terms, rarely occurring, are less familiar and thus demand a higher effort in terms of decoding, than commonly used terms" [10]. Terms possessing a low level of awareness among the reader are referred to as foreign words. This includes English expressions and technical terms as well as German terms which are less common. Ownby stated that "...complexity of vocabulary is the most consistent aspect of text that differentiates text ... whose overall ratings indicate that they are easier or more difficult to read" [11]. Ziefle and Bay also suggest that foreign words, acronyms and technical terms are to be avoided [12].
Thus, only terms with a high level of awareness are to be used [13], or if unavoidable, adequate descriptions are to be delivered to the reader [8].

\subsubsection{Signal words}

Signal words do not provide new content but rather point out certain aspects of semantic content or text structure e.g. eventually, at last, in order to [14]. They facilitate comprehension of certain textual structures and help to establish a correct, coherent and representative structure of the text [15]. Hence, as signal words reduce cognitive load [16], especially the elderly should benefit from their use [5].

\subsubsection{Passive voice}

A central aspect of designing technologies is the fulfillment of user expectations and desires. Especially elderly expect target group oriented addressing e.g. "direct addressing of the user" [8]. It was shown by Obler et al. that the use of passive phrasing increases difficulties in text comprehension [17]. This was also shown by Ownby in a more recent study [11].

\subsection{Layout factors}

In consideration of design aspects, the visual accentuation of various elements as well as the overall structure were analyzed. Other ergonomic aspects such as contrast of color, typeface, font size etc. were not evaluated in this study, as there has already been sufficient research on those factors.

\subsubsection{Visual signaling}

Signals reducing the cognitive load for understanding a text may not only be sent through words. Signals may also be sent acoustically or visually. The acoustic emphasis on single words [18] finds its counterpart in the style and design of words e.g. font style, underlining, certain positioning [16]. Independant from signal type, elderly generally benefit from elements capturing their attention [13].

\subsubsection{Visual structuring}

Changes in spatial layout can have significant consequences on accuracy and speed of comprehension [19]. Cohen stated that age differences are less evident if the transported information is well structured [20]. This finding is consistent with the results of the survey done by Jakobs et al. [8]. 39.6\% of the subjects replied to the question "what irritates you the most about instruction manuals?" that they are con- 
fusing. Further, an irritating structure and imprecise step by step instructions were critized [8].

A well structured text allows the reader to easily switch between the written instructions and a technical device [21]. Segmentations mark the spots, where the user may take a break from reading the manual, in order to execute the given instruction. Further, they enable easy navigation through the text, thus reducing the probability of repeating or skipping an instructional step [5].

\section{Empirical Study}

In order to gain an understanding of the process, the study design and dependent and independent variables are explained. Further, the group of subjects is outlined.

\subsection{Study design}

The test carried out was a reaction test. A reaction test asks the subjects to execute written instructions presented to them. Their reaction, measured in time needed to complete the task and the amount of errors made during the execution, allows to draw conclusions regarding the general textual comprehension [10]. In this study, the subjects were asked to execute instructions presented on a 10 inch tablet pc with touch screen. In order to minimize quantifiable effects created by age related change in the subject's visual reception, font size 18 was chosen for the entire text [13]. It was also decided to use a sans-serif typeface [22]. Further, the screen was positioned according to the anthropometric position of the subject. There were three different types of instructions in four different modes each. These four versions consist of the combination of two independent variables:

1.) Iconic vs. non-iconic formulation

2.) Other supportive layout and linguistic factors incorporated vs. other supportive layout and linguistic factors not incorporated

Among the instructions the following types were differentiated:

1.) The type "place pills" (P) asked the subjects to arrange pills of different colors in a pill box according to a particular order described in the instruction.
2.) Instructions of the type "make appointment" $(\mathrm{N})$ asked the subject to navigate through the environment of the tablet $\mathrm{pc}$ and make an appointment for a certain service e.g. a cleaning lady, on a certain day and time.

3.) "Body coordination" (M) demanded the coordination of movement, e.g. right hand to chin and left hand above head.

These instructions were given to the subjects in varying sequences. The construction of sequences was done according to the Williams design. The Williams design is a special case of the cross-over and Latin square designs. A Latin square, in which every treatment is represented once, and once only, in each column and in each row, yields uniform cross-over designs. Such a cross-over design is said to be balanced with respect to first-order carry-over effects [23]. Distinctive for this design is that each variation occurs only once during each sequence and at a different position in each sequence.

Thus, every subject participated in four test sequences. Each of those four test sequences consisted of three instructions with each instruction type $(\mathrm{P}, \mathrm{N}, \mathrm{M})$ occurring only once in each sequence and no formulation version (A, B, C, D) occurring twice in each sequence. Additionally, the order of versions in each sequence varied. This reduced positioning effects for later analysis. There was also a $30 \mathrm{~min}$. break between each sequence in order to reduce learning effects. Dependant variables are, as previously mentioned, execution time required $(\mathrm{t})$ and error rate $(\mathrm{F})$.

\subsection{Subjects}

45 subjects were tested. Eight of those participated in the pretest. The other 37 took part in the actual data collection. Of those 37 , one was excluded due to the fact, that he was not a native German, so difficulties in text comprehension could not be clearly associated with the factors evaluated. 24 subjects were male, 12 female. The age group of 61 years to 70 years was represented by $47.2 \%$ of the subjects, while $33.3 \%$ were between 71 and 80 years, $11.1 \%$ were aged between 50 and 60 years. $8,3 \%$ were between age 81 and 90 years.

\section{Results}

During the analysis ANOVAs were created for reaction time and amount of mistakes of all instructions. 
Here, time $(\mathrm{p}=0.03)$ and mistake evaluation $(\mathrm{p}=0.00)$ lead to significant differences during the application of temporal iconicity. Hence, iconic formulations seem to be more comprehensive than non iconic formulations. The average mistake for instructions of the category $\mathrm{A}$ and $\mathrm{B}$ was $\varnothing \mathrm{F}=0.5$ (SD 0.84 ), while instructions of category $C$ and $D$ were at $\varnothing \mathrm{F}=1.78$ (SD 1.86). The time average for instructions of category $\mathrm{A}$ and $\mathrm{B}$ was at $\varnothing \mathrm{t}=90.57 \mathrm{~s}$ (SD 43.78), $C$ and $D$ resulted in $\varnothing \mathrm{t}=106.34 \mathrm{~s}(\mathrm{SD} 60.75)$. A Bonferroni test showed no significant differences for time and error results in between the two iconic/ non iconic versions respectively though.

Looking at the means for each instruction type, it stands out that both instructions of category $\mathrm{P}$ and $\mathrm{M}$, show lower error rates in version $\mathrm{B}$ than instructions formulated in version $\mathrm{A}$. $\mathrm{M}$ received in version $\mathrm{A}$ $8.25 \%$ more mistakes than instructions of type B. Instructions of group $\mathrm{P}$ received even $35.38 \%$ more mistakes in variation $\mathrm{A}$.

However, subjects took approximately $6.5 \%$ more time in version B of group $\mathrm{M}$. The difference between version $\mathrm{A}$ and $\mathrm{B}$ was at $9.88 \%$ in time for instructions of group $\mathrm{P}$, inclining towards A. Correlation coefficients between time and error rates were computed in order to detect traces of time-accuracy trade-offs, but the results showed no sign thereof.

The calculated means for time and error rate include all results from all tested subjects. Considering the great intra-individual performance differences between the subjects, a more differentiated look on the results might be necessary in order to determine which formulation type obtained the best results. Therefore, for each subject was determined in which formulation type the best and worst outputs were produced. This was done for all instruction categories. Afterwards results were compared again.

This comparison of worst and best output showed that formulation type D is always joined with the highest amount of worst results - both for time and for error rates in all instruction categories. Thus in formulation type D $36.11 \%$ of the subjects performed worst time-wise in the category $\mathrm{P}$, even $41.67 \%$ in categories $\mathrm{N}$ and $\mathrm{M}$. Instructions in type $\mathrm{D}$ lead to $22.22 \%$ of the worst results error-wise in category $\mathrm{N}$ and up to $42.86 \%$ in category $P$.

In contrast most of the best results were joined with formulation type A. The only exception is the finding for best time results in category $\mathrm{M}$. There $38.89 \%$ of the best performances were achieved in connection with formulation type B. All the other "best performance" outcomes, up to $44.44 \%$, were linked to formulation type A.

At last, influencing factors were calculated in a multivariate data analysis.

It turned out that regarding the error rate the type of formulation and frequency of computer use were always influencing factors. So it can be said that besides the way of formulation, a strong effect roots back to the general use of computer systems. The analysis of a questionnaire completed prior to the test, states that $21.6 \%$ of the subjects never used a computer before. $45.9 \%$ operate a computer on a daily basis, $21.6 \%$ use it 2-3 times a week. $10.8 \%$ rarely use a computer. The difference in time and error results, between those who have never used a computer and those who have some level of experience with a computer system, is highly significant $\left(\mathrm{p}_{\mathrm{t}}=0.00\right.$; $\left.\mathrm{p}_{\mathrm{F}}=0.00\right)$. The mean for mistakes made by computer users was at $\varnothing \mathrm{F}=0.97$ (SD 1.41) mistakes per instruction, while the group that never used a computer system was at $\varnothing \mathrm{F}=1.84$ (SD 1.99) mistakes per instruction. The means for time were $\varnothing \mathrm{t}=113.32 \mathrm{~s}$ (SD 70.14) for the non users and $\varnothing \mathrm{t}=94.87 \mathrm{~s}$ (SD 48.05) for the experienced.

\section{Conclusion}

The study results imply that temporal iconicity plays a key role in the design of instructions. Instructions that were temporally iconic were executed faster and at a smaller error rate than instructions that were non iconic. A detailed evaluation of the other factors relevance was not possible within the frame of this study but looking at the differences regarding time and error rate between the non iconic versions $\mathrm{C}$ and $\mathrm{D}$, instructions that respect other supporting factors as active voice, text structure, signal wording and avoidance of foreign words, perform better with regard to the evaluated variables.

An explanation why most results for instruction category $\mathrm{M}$ were best performed in formulation type $\mathrm{B}$, might be, that some of the subjects were confused by the layout structure of the instructions provided in version A. Just as inappropriate accentuation slows language processing [18], a text structure that does not appeal to the reader might rather hinder than support textual understanding [24]. $11.1 \%$ of the probands stated in a questionnaire that was conducted right after the experiment, that they found the structural layout not helpful. 
As for the reason why computer use seems to play such a significant role in the overall results, it can only be assumed, that since the entire instructions were presented on a tablet pc, those with a certain amount of experience in computer use benefited from their know-how with a more confident and less anxious approach which ultimately resulted in higher performance levels.

The study focused on an age group above 50 years. However, ergonomic design of instruction manuals has an independent positive effect on comprehension of instructions and thus results in an increased impression of control on the user side - independent of age.

\section{Acknowledgment}

This research is funded by the German Federal Ministry of Education and Research BMBF (01FG10004) and the body responsible for the project is DLR.

\section{References}

[1] Wirtz, S., Jakobs, E., M. \& Ziefle, M. (2009). Age-specific usability issues of software interfaces. Proceedings of the IEA $2009-17$ th World Congress on Ergonomics (Bejing, China. CD-Rom).

[2] Smith, S. W., Rebok, G. W., Smith, W. R., Hall, S. E., \& Alvin, M. (1983). Adult age differences in the use of story structure in delayed free recall. Experimental Aging Research, 9(3), 191-195.

[3] Enkvist, N. E. (1981). Experiential iconicism in text strategy. Text, 1(1), 97-111.

[4] Haspelmath, M. (2003). Against Iconicity and Markedness. (http://email.eva.mpg.de/ haspelmt/IconicityMarkedness.pdf)

[5] Van Horen, F., Jansen, C., Noordman, L. \& Maes, A. (2009). Manuals for the elderly: Text characteristics that help or hinder older users. In Hayhoe, G. F \& Grady, H. M (Hrsg.) Connecting people with technology - Issues in professional communication (S. 43-53). New York: Baywood Publishing Company, Inc.

[6] Maxim, J. \& Bryan, K. (1994). Language of the elderly: A clinical perspective. London: Whurr Publishers, Ltd.

[7] Mc Daniel, M., A., Einstein, G., O. \& Jacoby L., L. (2008). New considerations in aging and memory: The glass may be half full. In Craik, F., I. \& Salthouse, T., A. (Hrsg.) The Handbook of Aging and Cognition (S. 251-310). New York: Psychology Press.
[8] Jakobs, E. M., Lehnen, K. \& Ziefle, M. (2008). Alter und Technik - Studie zu Technikkonzepten, Techniknutzung und Technikbewertung älterer Menschen. Aachen: Apprimus Verlag.

[9] Stephanidis, C. (2009). The Universal Access Handbook. New York: CRC Press.

[10]Amstad, T. (1978). Wie verständlich sind unsere Zeitungen? Abhandlung zur Erlangung der Doktorwürde der Philosophischen Fakultät I der Universität Zürich. Zürich: StudentenSchreib-Service.

[11] Ownby, R., L. (2005). Influence of Vocabulary and Sentence Complexity and Passive Voice on the Readability of Consumer-Oriented Mental Health Information on the Internet. AMIA 2005 Symposium Proceedings. 585-588.

[12]Ziefle, M. \& Bay, S. (2005). How older adults meet complexity: aging effects on the usability of different mobile phones. Behaviour \& Information Technology 24 (5), 375-389.

[13]Fisk, A., D., Rogers, W., A., Charness, N., Czaja, S., J. \& Sharit, J. (2004). Designing for older adults - Principles and Creative Human Factors Approaches. New York: CRC Press.

[14] Meyer, B. J. F. (1975). The organization of prose and its effects on memory. Amsterdam: North Holland Pub. Co.

[15]Lorch, R.F., Jr., \& Lorch, E.P. (1996). Effects of organizational signals on free recall of expositorytext. Journal of Educational Psychology, 88, 38-48

[16] Meyer, B. J. F., Marsiske, M. \& Willis, S. L. (1993). Text processing variables predict the readability of everyday documents read by older adults. Read Res Q, 28(3)

[17] Obler, L.K., Nicholas, M., Albert, M. L., Woodward, S. (1985). On comprehension across the adult lifespan. Cortex, 21, 273-280.

[18]Cohen, G. \& Faulkner, D. (1986). Does "Elderspeak" work? The effect of intonation and stress on comprehension and recall of spoken discourse in old age. Language \& Communication, 6, 91-98.

[19]Detweiler, M., C. \& Ellis, R., D. (1996). The Effects of Display Layout on Keeping Track of Visual-Spatial Information. In Rogers, W., A., Fisk, A., D. \& Walker, N. (Hrsg.) Aging and Skilled Performance. (S.157-184). Mahwah: Lawrence Erlbaum Associates, Inc. Publishers.

[20]Cohen, G. (1987). Speech comprehension in the elderly. British Journal of Audiology, 21, 221-226.

[21] Steehouder, M., \& Karreman, 1. (2000). De verwerking van stapsgewijze instructies. Tijdschrift voor Taalbeheersing, 22 218-237.

[22] Hartley, J. (1994). Designing instructional text for older readers: A literature review. In: British Journal of Educational Technology 25, 172-188.

[23] Wang, B. S., Wang, Li, X. J. \& Gong, L. K. (2009). The Construction of a Williams Design and Randomization CrossOver Clinical Trials Using SAS. Journal of Statistical Software, 29. (Über: http://www.jstatsoft.org, zuletzt besucht Juni 2011)

[24]Kauffman, D. F., Kiewra, K. A. (2010). What makes a matrix so effective? An empirical test of the relative benefits of signaling, extraction, and localization. In: Instructional Science 38 (6). 679-705. 